Old Dominion University

ODU Digital Commons

\title{
Using Heat to Trace Vertical Water Fluxes in Sediment Experiencing Concurrent Tidal Pumping and Groundwater Discharge
}

\author{
N. K. LeRoux \\ B. L. Kurylyk \\ M. A. Briggs \\ D. J. Irvine \\ J. J. Tamborski \\ Old Dominion University, jtambos@odu.edu
}

See next page for additional authors

Follow this and additional works at: https://digitalcommons.odu.edu/oeas_fac_pubs

Part of the Oceanography Commons

\section{Original Publication Citation}

LeRoux, N. K., Kurylyk, B. L., Briggs, M. A., Irvine, D. J., Tamborski, J. J., \& Bense, V. F. (2021). Using heat to trace vertical water fluxes in sediment experiencing concurrent tidal pumping and groundwater discharge. Water Resources Research, 57(2), 1-13, Article e2020WR027904. https://doi.org/10.1029/2020wr027904

This Article is brought to you for free and open access by the Ocean \& Earth Sciences at ODU Digital Commons. It has been accepted for inclusion in OES Faculty Publications by an authorized administrator of ODU Digital Commons. For more information, please contact digitalcommons@odu.edu. 


\section{Authors}

N. K. LeRoux, B. L. Kurylyk, M. A. Briggs, D. J. Irvine, J. J. Tamborski, and V. F. Bense 


\section{Water Resources Research}

\section{RESEARCH ARTICLE \\ 10.1029/2020WR027904 \\ Key Points: \\ - Temperature and hydraulic head \\ Using Heat to Trace Vertical Water Fluxes in Sediment Experiencing Concurrent Tidal Pumping and Groundwater Discharge} exhibit multi-frequency periodicity in coastal sediment due to diurnal and semi-diurnal forcing

- Multi-frequency signal convolution complicates application of methods using diurnal temperature signals to trace vertical water exchange

- These limitations can be overcome by using dynamic sediment porewater head and temperature in conjunction to estimate water fluxes

Supporting Information:

- Supporting Information S1

- Data Set S1

- Data Set S2

- Data Set S3

- Data Set S4

- Data Set S5

- Data Set S6

- Data Set S7

- Data Set S8

- Data Set S9

- Data Set S10

Correspondence to:

B. L. Kurylyk,

barret.kurylyk@dal.ca

Citation:

LeRoux, N. K., Kurylyk, B. L., Briggs, M. A., Irvine, D. J., Tamborski, J. J, \& Bense, V. F. (2021). Using heat to trace vertical water fluxes in sediment experiencing concurrent tidal pumping and groundwater discharge. Water Resources Research, 57, e2020WR027904. https://doi. org/10.1029/2020WR027904

Received 7 MAY 2020

Accepted 23 DEC 2020

Abstract Heat has been widely applied to trace groundwater-surface water exchanges in inland to estimate water fluxes. We investigate the convolution of thermal and hydraulic signals to assess the groundwater discharge. We first generate sediment temperature and head time series for conditions and tidal head signals. We then analyze these synthetic temperature time series using heat tracing estimated the mean discharge fluxes in most cases but could not reproduce the flux variability within magnitude and direction can be accurately estimated if paired temperatures and hydraulic heads are instrumentation to better assess sub-daily flux oscillations and associated reactive processes. These interactions can influence the temperatures and chemistry of coastal water bodies and impact to better understand their impacts on coastal water quality. Presently, it is challenging to accurately temperature and groundwater pressure data can be measured and analyzed to estimate these vertical

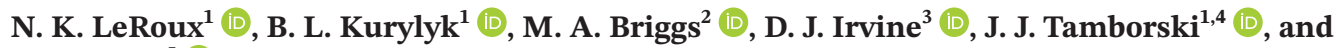 \\ V. F. Bense ${ }^{5}$ (D) \\ ${ }^{1}$ Centre for Water Resources Studies and Department of Civil and Resource Engineering, Dalhousie University, Halifax, \\ NS, Canada, ${ }^{2}$ US Geological Survey, Hydrogeophysics Branch, Storrs, CT, USA, ${ }^{3}$ Research Institute for the Environment \\ and Livelihoods, Charles Darwin University, Casuarina, Northern Territory, Australia, ${ }^{4}$ Department of Ocean and \\ Earth Sciences, Old Dominion University, Norfolk, VA, USA, ${ }^{5}$ Department of Environmental Sciences, Wageningen \\ University and Research, Wageningen, the Netherlands
} environments, but it is infrequently applied in coastal sediment where head oscillations induce periodicity in water flux magnitude/direction and heat advection. This complicates interpretation of temperatures viability of using heat as a tracer in environments with tidal head oscillations superimposed on submarine ranging from no tide to mega-tidal using a numerical model (SUTRA) forced with periodic temperature software (VFLUX2 and 1DTempPro) to evaluate if conventional terrestrial approaches to infer fluxes from temperatures are applicable for coastal settings. We consider high-frequency water flux variability within a tidal signal and averaged over tidal signals. Results show that VFLUX2 analytical methods reasonably tidal cycles. The model results further reveal that high-frequency time series of water fluxes varying in analyzed using numerical models (e.g., 1DTempPro) that consider both dynamic hydraulic gradients and thermal signals. These results point to the opportunity to incorporate pressure sensors within heat tracing

Plain Language Summary Coastal water bodies are hydrologically connected to underlying aquifers or sediment, which allows for exchanges of water, heat, and chemicals between these domains. ecosystems. Thus, it is important for us to measure the variability of these exchanges in space and time measure how these exchanges vary in time due to tidal variability. In this study, we propose that sediment exchanges in coastal settings. We use model results to reveal that if both the temperature and water pressure in coastal sediments are recorded, models can be applied to interpret measured data and quantify exchange between coastal sediment and overlying coastal water bodies.

\section{Introduction}

The biogeochemistry, ecosystem productivity, and diversity of coastal environments can be strongly influenced by the spatiotemporal distribution of ocean-sediment exchanges of water, solute, and heat (Robinson et al., 2018; Taniguchi et al., 2019). These fluxes are mediated by variable-density flow and hydraulic gradients induced by waves, tides, seasonal groundwater level variations, and sea-level rise (Hutchinson et al., 2009; Michael et al., 2005; Robinson et al., 2007; Sawyer et al., 2016). The appropriate terminology for these water fluxes has been debated (Santos et al., 2012; Wilson et al., 2016) due in part to the difficulty in distinguishing between shallow saline exchange fluxes (Russoniello et al., 2018) and fresh submarine 
groundwater discharge (Moore, 2010). In this study, "vertical water flux" refers to the upward or downward component of any porewater flux within the sediment. We consider the mean upwelling flux averaged across one or more tidal signal(s) to be the "background" terrestrial groundwater discharge (Burnett et al., 2003; Taniguchi et al., 2019), and the high-frequency vertical flux oscillations to be tidal pumping superimposed on these background conditions. A variety of methods for measuring vertical water fluxes in coastal settings have been developed, including seepage meters and isotopic tracers such as radon and radium (Burnett et al., 2006; Swarzenski, 2007; Taniguchi et al., 2002). Isotopic tracers often only yield values averaged across larger spatial scales. Seepage meters offer the only "direct” discharge flux measurement, but are labor intensive, difficult to maintain over multi-day deployments, and restricted to calm conditions (Duque et al., 2020).

Heat is a potentially powerful tracer of vertical water fluxes in coastal sediment due to the interrelationships between vertical water fluxes, heat advection, and subsurface temperatures (Anderson, 2005). Heat has been widely applied to trace groundwater-surface water exchanges in inland surface water bodies such as streams, rivers, and lakes as detailed in prior reviews (Constantz, 2008; Irvine et al., 2017; Kurylyk et al., 2019; Rau et al., 2014). However, these methods have only rarely been applied in tidal estuaries (Befus et al., 2013; Henderson et al., 2009), lagoons (Swain \& Prinos, 2018; Tirado-Conde et al., 2019) or offshore environments (Goto et al., 2005; Kurylyk et al., 2018; Wilson et al., 2016). To our knowledge, previous studies have not directly addressed the influence of tide-driven oscillations in vertical water fluxes when using conventional heat as a tracer techniques. Prior studies have typically been aimed at estimating the net mean flux rate, missing potentially important physical processes in tidal settings, such as flux direction reversal to downwelling at high tide. Although quantifying net groundwater exchange is important for coastal water budgets, short-term vertical flux variations can influence biogeochemical conditions, such as porewater redox gradients created by tidal pumping of oxic seawater and other reactants into reducing sediments (Reckhardt et al., 2015).

In this study, we investigate whether standard analytical and numerical heat tracing methods that estimate vertical water fluxes based on the downward propagation of diurnal temperature signals are applicable in tidal environments. Analytical methods based on diurnal temperature signals rely on the phase shift and/ or amplitude ratio between paired sediment temperature signals at two or more depths (Hatch et al., 2006; Keery et al., 2007; Luce et al., 2013; McCallum et al., 2012). These are implemented in VFLUX2 (Irvine et al., 2015a), which uses dynamic harmonic regression to determine phase shifts and amplitude ratios. Analytical approaches assume that the vertical water flux is uniform and steady; when the vertical flux varies, the analytical solutions become approximate. While prior studies have shown that reliable estimates of time-varying fluxes can be obtained in certain conditions (Irvine et al., 2015a, 2017; Lautz, 2012; Rau et al., 2014), the influence of high-frequency (e.g., hourly) variability in vertical fluxes has not been investigated using these methods. We hypothesize that these analytical approaches may not be able to capture sub-daily flux dynamics where tidal cycles induce variations in the magnitude, and potentially direction, of hydraulic gradients and water fluxes. These oscillations potentially impact diurnal signal propagation and create issues when extracting sinusoidal components via signal processing (Irvine et al., 2015a). Heat tracing models that use numerical approaches, such as 1DTempPro (Koch et al., 2016; Voytek et al., 2013), may help to overcome these challenges as there is potential to incorporate dynamic head gradient data. However, numerical techniques are less commonly employed than $1 \mathrm{D}$ analytical heat tracing methods. Our overall goals in this study are to (1) investigate if heat can be applied to trace sub-daily vertical water flux variability and flux direction reversals in tidal settings, and (2) use results from (1) to provide guidance on instrumentation and data analysis techniques for applying heat as a tracer in coastal settings.

\section{Methods}

We considered three models in this study to first generate synthetic temperature and head fields and then analyze these data using heat as a tracer software tools (Figure 1a). We first applied the numerical groundwater flow and transport model SUTRA (Voss \& Provost, 2019) in 1D to forward model head, temperature, and vertical water flux fields subject to diurnal and semi-diurnal surface boundary conditions. Since the SUTRA-modeled water fluxes were known at each point in time and space, standard heat tracing software 
(a) Flow chart of modeling process

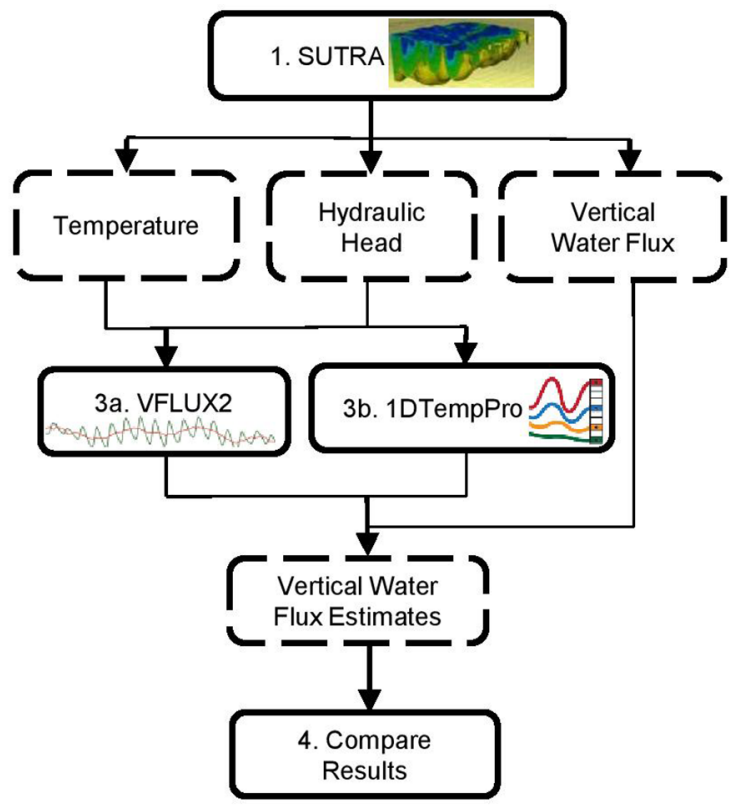

(b) SUTRA domain and boundary conditions

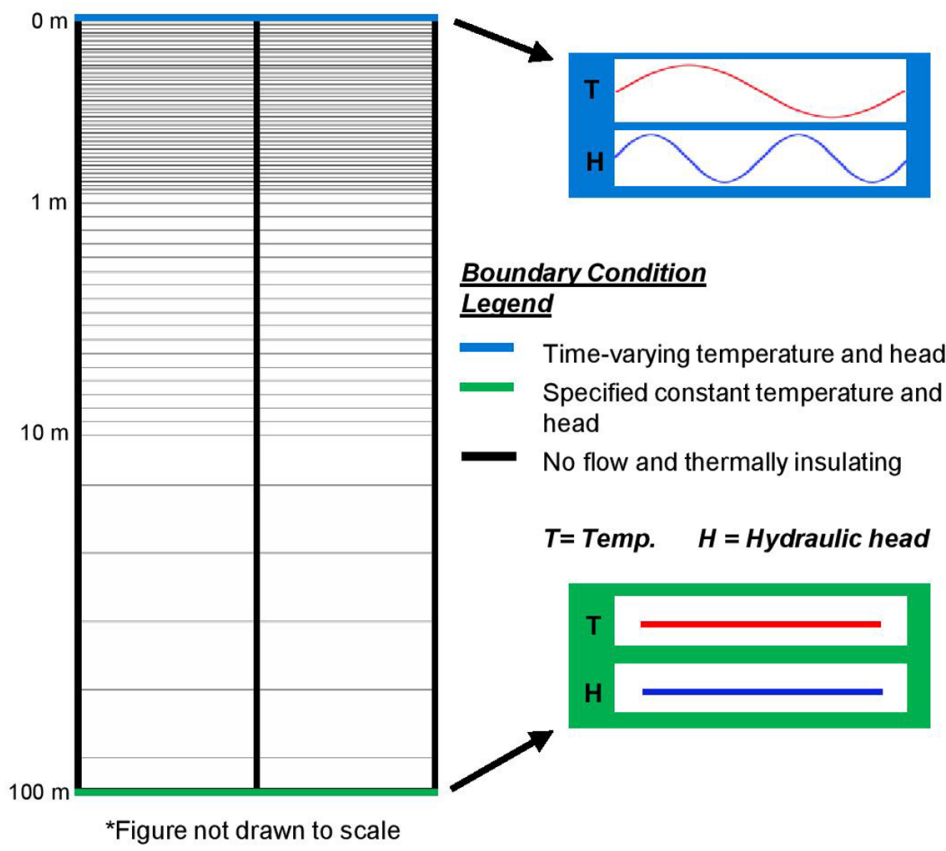

Figure 1. (a) Flowchart indicating modeling and data processing steps. Dashed boxes indicate model outputs. (b) SUTRA domain and boundary conditions with the vertical extent shown on a log scale. The actual finite element mesh used in SUTRA was much denser than that shown in (b).

packages (VFLUX2 and 1DTempPro) were used in an inverse manner to investigate the ability of these tools to process the SUTRA-simulated results and reproduce the known vertical fluxes under tidal forcing.

\subsection{Numerical Model of Groundwater Flow and Heat Transport}

We used SUTRA to simulate water flow and energy transport in coastal sediment and generate a data set for analysis. We created a simplified model (Figure 1b) with fully saturated conditions, homogeneous thermal and hydraulic properties, constant water density and viscosity, and only vertical flow and heat transport. These simplifications were useful to allow us to focus on the overarching goal of investigating the convolution of periodic thermal and hydraulic signals at different frequencies. Also, we restricted simulations to the vertical dimension to align with assumptions underlying VFLUX2 and 1DTempPro. Flow is multi-dimensional along coastal shorelines (e.g., Robinson et al., 2007), but is often more vertical in wide, coastal water bodies such as the beds of lagoons (Tirado-Conde et al., 2019) or harbors. The influence of multi-dimensional flow on 1D heat tracing methods has been rigorously investigated elsewhere, and prior studies have generally concluded that $1 \mathrm{D}$ heat tracing techniques yield the vertical component of 2D or 3D flow vectors (e.g., Cuthbert \& Mackay, 2013; Irvine et al., 2015b). Without multiple dimensions, free convection does not occur, but variable-density conditions can still exist and influence system properties. We conducted preliminary modeling results with variable-density conditions, but the results were almost identical to those with constant density. Thus, for simplicity, variable-density flow was not considered in the model results discussed herein.

As our primary focus was the interference of tidal hydraulic signals and diurnal thermal signals, all conditions and parameters were constant among runs except for the top boundary conditions. For our first set of runs, we imposed periodic hydraulic head (12.42-h period, M2 tidal constituent) and temperature signals (24-h period) on the SUTRA surface boundary. For head, we considered no tide, micro-tidal, macro-tidal, and mega-tidal conditions with tidal amplitudes of $0,0.5,2.5$, and $5 \mathrm{~m}$, respectively. The mean surface temperature was $15^{\circ} \mathrm{C}$, and the diurnal temperature amplitude was $5^{\circ} \mathrm{C}$, which is typical for summer conditions in shallow coastal waters (e.g., McCabe et al., 2010). At the bottom boundary, we assigned constant 
SUTRA results at depths $(\mathrm{m})-0-0.1-0.2-0.3-0.5$

(a)

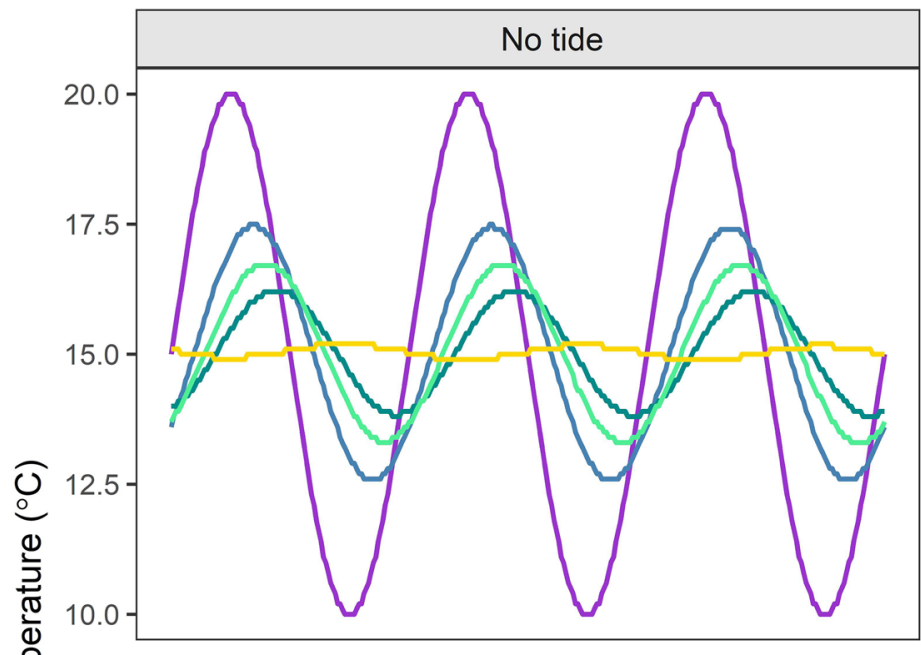

(c)

迹

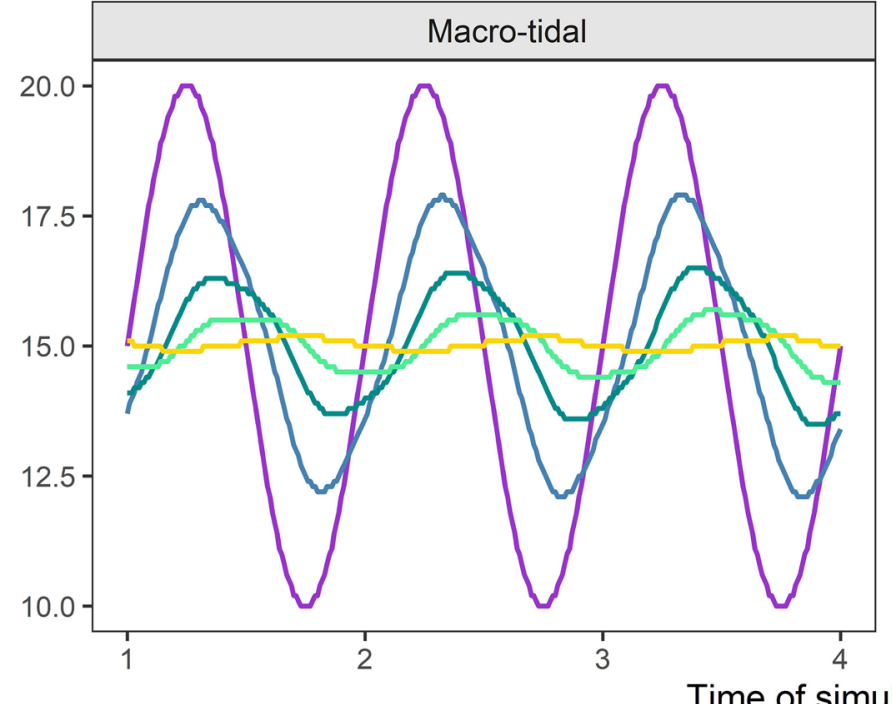

(b)

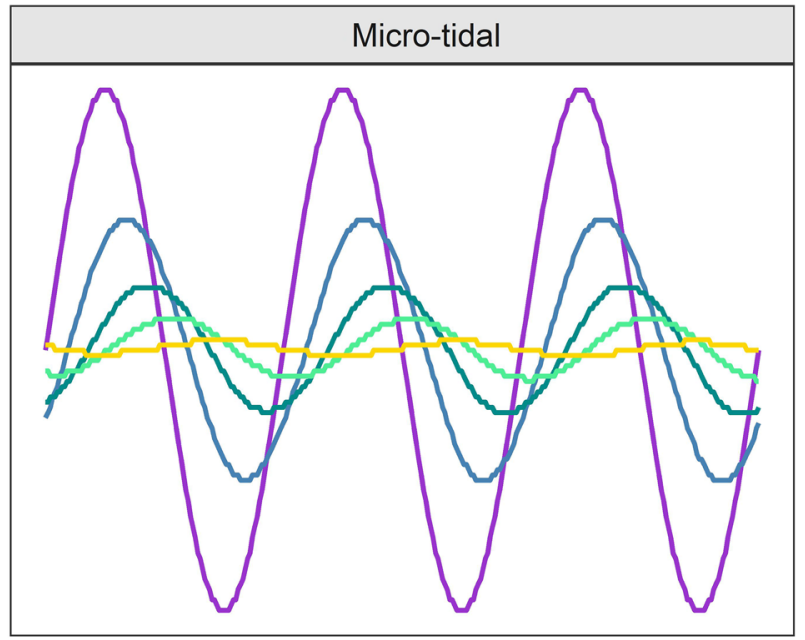

(d)

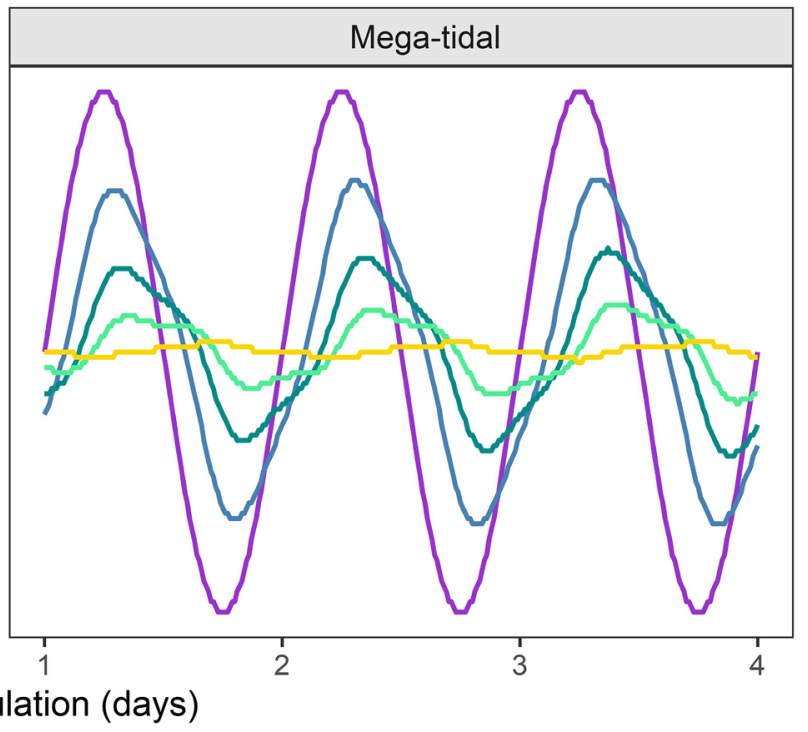

Figure 2. SUTRA-simulated porewater temperature versus time for five depths and four tidal conditions.

temperature and head conditions (Figure 1b); a 100-m bottom depth was required to ensure the lower boundary did not impact the shallow hydraulic signal propagation. We set hydraulic conductivity to be $1 \times 10^{-4} \mathrm{~m} \mathrm{~s}^{-1}$ (clean sand, Freeze \& Cherry, 1979) and a tidally averaged downward hydraulic gradient of 0.01 to produce an average flux of $-1 \times 10^{-6} \mathrm{~m} \mathrm{~s}^{-1}$ (negative denotes upward), which is typical for groundwater upwelling rates in coastal settings (e.g., Bokuniewicz et al., 2004; Michael et al., 2005). To account for the influence of total stress change due to surface tidal signals and the fact that effective stress is no longer inversely related to porewater pressure (Reeves et al., 2000; Xin et al., 2012), we set the matrix compressibility to 0 (see Figure 3 in Gardner \& Wilson, 2006) but retained water compressibility. Table S1 lists all boundary conditions and parameters used in SUTRA.

We spun up this first set of model runs from initial conditions of a uniform 0.01 hydraulic gradient and uniform domain temperature equal to the mean surface temperature. We ran 15-day transient simulations with a constant time step (0.01 days) and element heights ranging from $0.005 \mathrm{~m}$ at the top to $1 \mathrm{~m}$ at the bottom. This spatiotemporal discretization produced accurate results when simplified runs were compared 
to hydraulic and thermal analytical solutions (Figure S1 and S2); however, no thermal analytical solution exists for our conceptual model with periodic water fluxes and concomitant heat advection. For these runs, the model achieved approximate dynamic equilibrium conditions with the repeating thermal and hydraulic boundary conditions in $<1.5$ days.

We forced the four runs (no tide, micro-tidal, macro-tidal, and mega-tidal) described above with simplistic, repeating, periodic boundary conditions as these runs were intended to focus on the interactions between thermal and hydraulic periodic signals. However, actual field data are more complex. For example, we assumed that coastal water temperature oscillates with a period of 1 day (e.g., Kawai \& Wada, 2007; Morris \& Taylor, 1983), but semi-diurnal surface water temperature variations are common in coastal settings when tidal exchange exerts thermal control (e.g., Wilson et al., 2016). Also, tidal signals do not merely repeat on semi-diurnal cycles as in our four runs above but are rather characterized by many tidal constituents operating at different frequencies (Hendershott \& Munk, 1970). To investigate the influence of more complex, natural boundary conditions, we performed an additional simulation with the top boundary condition formed from previously published coastal water level and temperature data from a macro-tidal site (Baeksu tidal flat) on the southwestern coast of Korea (Kim \& Cho, 2011). We used the Fast Fourier Transform tool in Matlab (Math Works, Inc.) to extract approximations of the diurnal, semi-diurnal, and spring-neap constituents for head and the diurnal and semi-diurnal constituents for temperature, and assigned these superimposed sine waves for the top boundary conditions in SUTRA. As our objective with this model run was to investigate potential complications arising from boundary conditions with multiple thermal and hydraulic periodic constituents, all model parameters remained the same as in the other simulations.

\subsection{Heat as a Tracer Software Tools}

We analyzed the SUTRA-simulated temperature data in an inverse manner using VFLUX2 (Gordon et al., 2012; Irvine et al, 2015) and 1DTempPro version 2 (Koch et al., 2016; Voytek et al., 2013) to investigate if these programs could reproduce the known porewater fluxes (Figure 1a). VFLUX2 is based on 1D analytical solutions (Hatch et al., 2006; Keery et al., 2007; Luce et al., 2013; McCallum et al., 2012) and applies signal processing techniques to extract the sinusoidal component of temperature signals and produce a time series of vertical fluxes using the amplitude ratio and/or phase shift between multi-depth temperature signals. 1DTempPro is a user interface for a 1D version of VS2DH (Healy \& Ronan, 1996) designed for using heat as a groundwater tracer. Vertical water fluxes are altered in the model to match the temperature time series for the sensor(s) between the upper and lower thermal boundary conditions using either automated or manual calibration techniques. Additionally, if dynamic porewater head data are available at the boundaries, the 1DTempPro domain hydraulic conductivity can also be automatically estimated along with time-variable vertical flux, although this option is not often used due to a general lack of head data paired with temperature. Temperature data alone can be used in 1DTempPro to estimate time-variable fluxes, although without pressure data, model calibration is manual and requires the user to provide an initial 'guess' at the dynamic pattern.

We set all thermal properties in VFLUX2 and 1DTempPro to the same values as for SUTRA (Table S1) to allow us to analyze SUTRA-simulated temperature data and produce flux estimates. We extracted temperature time series from SUTRA nodes at depth intervals of $0.05 \mathrm{~m}$ and reduced the temperature resolution to $0.01^{\circ} \mathrm{C}$ to match resolution of typical field instrumentation. In VFLUX2, we applied the amplitude ratio methods (Hatch et al., 2006; Keery et al., 2007), which are robust in a variety of natural settings (Irvine et al., 2017), as well as the combined amplitude ratio/phase shift approaches (Luce et al., 2013; McCallum et al., 2012). Many combinations of paired temperature time series are available from the SUTRA results at $0.05 \mathrm{~m}$ depth intervals. Given that diurnal temperature signals did not penetrate far (see Results), we only considered SUTRA-simulated temperatures to a depth of $0.4 \mathrm{~m}$. VFLUX2 enables the user to consider different spacings between the paired temperature signals, and we performed analyses using $0.05 \mathrm{~m}$ and $0.1 \mathrm{~m}$ spacing, which is typical of spacing in field instrumentation (Briggs et al., 2014).

For 1DTempPro, we used the temperature time series over 15 days at the surface and at $0.2 \mathrm{~m}$ to form the upper and lower boundary conditions, respectively, as deeper temperatures proved to be less effective for estimating vertical fluxes. The solution to the inverse problem was obtained by minimizing the difference 
between the SUTRA-simulated and 1DTempPro-modeled temperatures at the intermediate depths $(0.05$, 0.10 , and $0.15 \mathrm{~m})$. Typically, hydraulic head data are not used in 1DTempPro to constrain vertical flux estimates, but rather to estimate hydraulic conductivity from Darcy's law in conjunction with water flux estimated from temperature. However, in this study, we also ran 1DTempPro with dynamic, paired hydraulic head data to help constrain vertical flux estimates within tidal signals. By including both VFLUX2 and 1DTempPro, the latter with and without head data, we considered (1) if there are limitations associated with analytical heat tracing solutions in these settings and, if so, whether numerical methods can overcome them and (2) whether combined head and temperature data can help disentangle complex hydraulic and thermal dynamics of porewater fluxes in tidal environments. For VFLUX2 and 1DTempPro with temperature and head data, we investigated if these methods could yield both the mean vertical flux across a tidal signal and the flux variability within a tidal signal. We attempted to model sub-daily tidal pumping using the temperature-only mode in 1DTempPro, but we were unable to reproduce flux variability with this mode. Thus, when we ran 1DTempPro with temperature data alone, we used a constant flux mode and only considered whether the mean flux across a tidal cycle could be determined. We also repeated these methods of analyses in VFLUX2 and 1DTempPro for the SUTRA results from the model run with more complex (field) data with multiple periodic constituents imposed on the top boundary.

\section{Results and Discussions}

\subsection{Numerical Model (SUTRA) Results}

SUTRA-simulated temperatures with the simple, periodic boundary conditions show that the hydraulic head (Figure S3) and temperature signals (Figure 2) are damped and lagged with depth in accordance with hydraulic (Jacob, 1950) and thermal (Stallman, 1965) theory. Hydraulic signals penetrate much further (e.g., $>30 \mathrm{~m}$, Figure S3) than the temperature signals $(<0.5 \mathrm{~m}$, Figure 2$)$, primarily because hydraulic diffusivity is several orders of magnitude larger than thermal diffusivity. For the simplified boundary conditions, the hydraulic signals penetrate downward and remain perfectly sinusoidal. In contrast, as the tidal amplitude increases, the temperature signals at depth increasingly deviate from perfect sinusoids (Figure 2). Tide-driven oscillations in water fluxes and heat advection cause the temperature signals to become more "sawtooth" at higher tidal ranges (Figure $2 \mathrm{c}$ and $2 \mathrm{~d}$ ). The sawtooth characteristics are not apparent at the surface due to the sinusoidal boundary condition or at the bottom where the signals (sawtooth and sinusoidal) are damped. But at intermediate depths (e.g., 0.2-0.3 m), SUTRA results diverge from sinusoids for macro- and mega-tidal conditions. We next investigate if standard analytical heat as a tracer approaches and related signal processing in VFLUX2 can still extract average fluxes or flux variability within a tidal signal.

\subsection{Heat as a Tracer Software Results}

We analyzed the SUTRA-simulated temperatures (Figure 2) in VFLUX2 to estimate vertical water fluxes with 240 different analyses due to the alternative signal depth pairs, analytical techniques, and tidal conditions. As illustrative examples, we present the results for the shallowest paired temperature signals (Figure 3, left column) as this depth pair consistently produced as good or better results than other depth pairs, except for mega-tidal conditions which produced "NaN" errors for many spacings (Figure 3d). As expected, all VFLUX2 methods produced reasonably accurate vertical water fluxes in the absence of tidal signals after about 2.5 simulation days (Figure 3a), which is the time required for the edge effects to be removed in signal processing (Hatch et al., 2006; Irvine et al., 2015a). The thermal amplitude ratio methods (Hatch et al., 2006; Keery et al., 2007) produced equivalent vertical water fluxes as observed in previous studies when thermal dispersivity is ignored (e.g., Irvine et al., 2017), and thus we do not distinguish results from these two methods. Similarly, the combined amplitude ratio and phase shift methods (Luce et al., 2013; McCallum et al., 2012) yielded equivalent vertical water fluxes.

VFLUX2 methods were incapable of reproducing high-frequency (intra-tidal) vertical flux variability (Figures $3 b-3 d$, left column) but reasonably estimated the mean vertical fluxes under micro- and macro-tidal forcing (Figure $3 \mathrm{~b}$ and $3 \mathrm{c}$ ), at least when averaged over the simulation period. The true (SUTRA) flux direction does not change for the micro-tidal run, but it does for the macro- and mega-tidal runs for which 


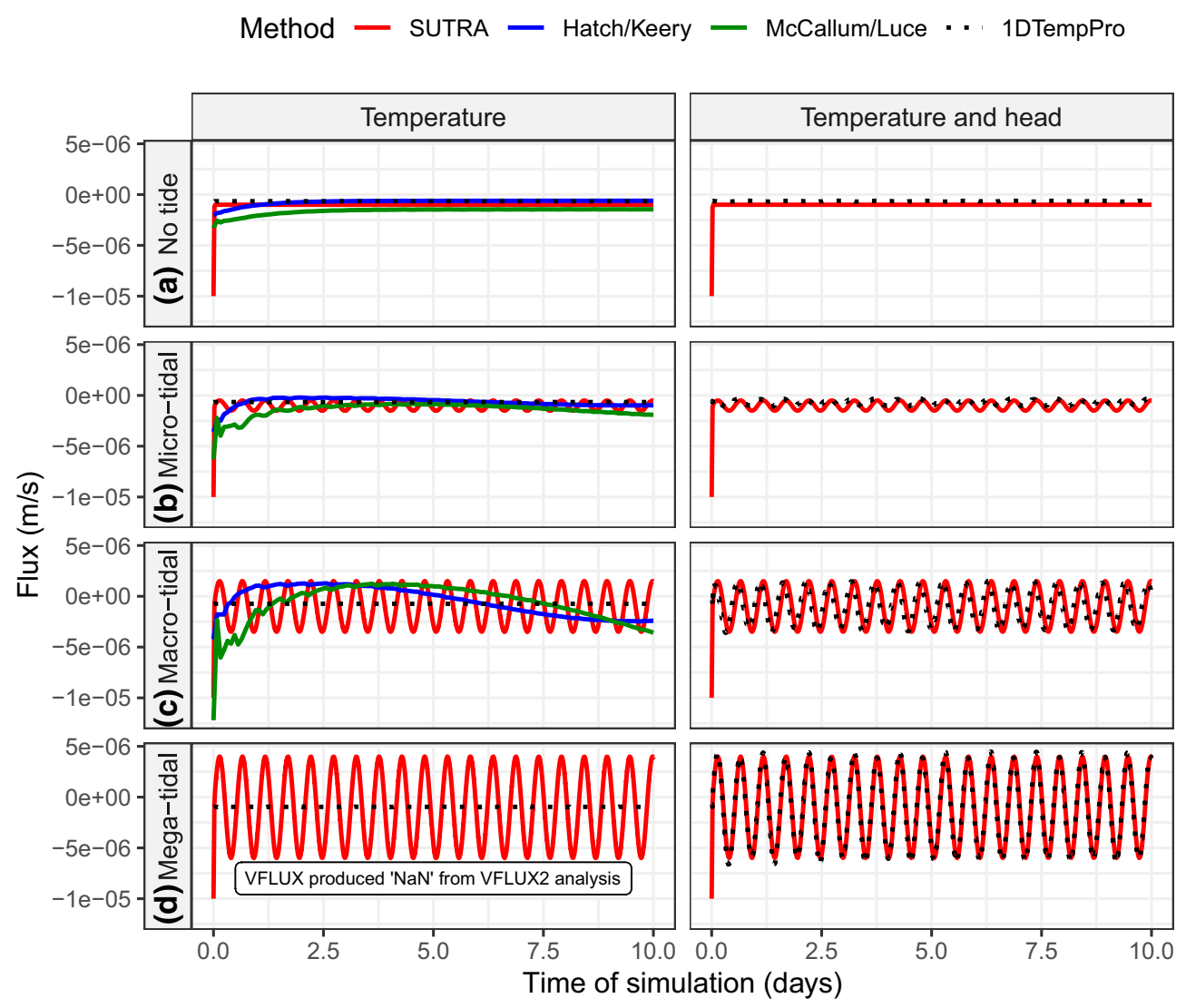

Figure 3. Flux results from VFLUX2 and 1DTempPro versus the true fluxes from SUTRA for four tidal conditions. Left panels show VFLUX2 and 1DTempPro results when temperature is the only input, and right panels show flux results when paired temperature and head are inputs to 1DTempPro.

the flux amplitude exceeds the flux mean (Figure 3c and 3d). The fluxes estimated in VFLUX2 exhibited sinusoidal variability with a period equal to the simulation duration rather than a tidal period, which we attribute to an artifact of the signal processing.

SUTRA-simulated time series were also analyzed in 1DTempPro. When only temperature data were analyzed (Figure 3a, left), the model performed reasonably well at reproducing the mean vertical water fluxes. Furthermore, when temperature data were considered with paired hydraulic head data (but without hydraulic conductivity), 1DTempPro generally reproduced the "known" fluxes within and across tidal signals for the tidal ranges considered (Figure 3, right). These results highlight the viability of using heat as a tracer in hydraulically complex regimes if temperature and head data are available.

Results in Figure 3 are also tabulated in comparison to the SUTRA-simulated fluxes (Table 1). For VFLUX2, the mean vertical water fluxes averaged across the entire simulation yielded errors that were $\leq 38 \%$ for the amplitude ratio methods, and $\leq 101 \%$ for the combined amplitude ratio and phase shift methods (Table 1a). These errors are generally acceptable for estimated fluxes considering that water fluxes inferred from hydraulic gradients alone rely on the estimation of $K$, which is often only known to an order of magnitude precision. The 1DTempPro results for when only temperature data were analyzed yielded relative errors for the inferred vertical fluxes $\leq 35 \%$ (Table 1b). In general, the results show that for tidal settings with a relatively constant background mean vertical flux, 1DTempPro can be used in constant flux mode with temperature data alone to accurately estimate this flux.

When both hydraulic head and temperature were considered in variable flux mode within 1DTempPro, the errors in the automatically estimated mean vertical water flux surprisingly decrease with increasing 
Table 1

VFLUX2 and 1DTempPro Results for Vertical Water Fluxes (Mean and Amplitude) and Root-Mean-Square-Error (RMSE) for Temperature (1DTempPro Results Compared to SUTRA)

(a) VFLUX2 results

\begin{tabular}{|c|c|c|c|c|c|c|}
\hline \multirow[b]{2}{*}{ Tide condition } & \multicolumn{3}{|c|}{ Hatch/Keery methods } & \multicolumn{3}{|c|}{ McCallum/Luce methods } \\
\hline & Estimated $\bar{q}(\mathrm{~m} / \mathrm{s})^{\mathrm{a}}$ & True $\bar{q}(\mathrm{~m} / \mathrm{s})$ & Relative errors (\%) & Estimated $\bar{q}(\mathrm{~m} / \mathrm{s})^{\mathrm{a}}$ & True $\bar{q}(\mathrm{~m} / \mathrm{s})$ & Relative errors (\%) \\
\hline No tide & $-6.2 \times 10^{-7}$ & $-1.0 \times 10^{-6}$ & -38 & $-1.46 \times 10^{-6}$ & $-1.0 \times 10^{-6}$ & 46 \\
\hline Micro-tidal & $-6.8 \times 10^{-7}$ & $-1.0 \times 10^{-6}$ & -32 & $-1.52 \times 10^{-6}$ & $-1.0 \times 10^{-6}$ & 52 \\
\hline Macro-tidal & $-9.6 \times 10^{-7}$ & $-1.0 \times 10^{-6}$ & -4 & $-2.01 \times 10^{-6}$ & $-1.0 \times 10^{-6}$ & 101 \\
\hline Mega-tidal & - & $-1.0 \times 10^{-6}$ & - & - & $-1.0 \times 10^{-6}$ & - \\
\hline
\end{tabular}

(b) 1DTempPro results when only analyzing temperature

\begin{tabular}{lcccc}
\hline Tide condition & Estimated $\bar{q}(\mathrm{~m} / \mathrm{s})^{\mathrm{a}}$ & True $\bar{q}(\mathrm{~m} / \mathrm{s})^{\mathrm{a}}$ & Relative $\bar{q}$ errors $(\%)$ & RMSE $\left({ }^{\circ} \mathrm{C}\right)$ between $1 \mathrm{DTempPro}$ and SUTRA \\
\hline No tide & $-6.5 \times 10^{-7}$ & $-1.0 \times 10^{-6}$ & -35 & 0.09 \\
Micro-tidal & $-6.5 \times 10^{-7}$ & $-1.0 \times 10^{-6}$ & -35 & 0.08 \\
Macro-tidal & $-7.3 \times 10^{-7}$ & $-1.0 \times 10^{-6}$ & -28 & 0.19 \\
Mega-tidal & $-9.5 \times 10^{-7}$ & $-1.0 \times 10^{-6}$ & -5 & 0.34 \\
\hline
\end{tabular}

(c) 1DTempPro results when analyzing both temperature and hydraulic head

\begin{tabular}{|c|c|c|c|c|c|c|}
\hline Tide Condition & Estimated $\bar{q}(\mathrm{~m} / \mathrm{s})^{\mathrm{a}}$ & $\begin{array}{c}\text { Relative } \bar{q} \text { errors } \\
(\%)^{\mathrm{a}}\end{array}$ & $\begin{array}{l}\text { Estimated } q \\
\text { amplitude }(\mathrm{m} / \mathrm{s})\end{array}$ & $\begin{array}{c}\text { True } q \text { amplitude } \\
\qquad(\mathrm{m} / \mathrm{s})\end{array}$ & $\begin{array}{l}\text { Relative errors (\%) } \\
\quad \text { for } q \text { amplitude }\end{array}$ & $\begin{array}{c}\text { RMSE }\left({ }^{\circ} \mathrm{C}\right) \text { between } \\
\text { 1DTempPro and } \\
\text { SUTRA }\end{array}$ \\
\hline No tide & $-6.5 \times 10^{-7}$ & -35 & $4.3 \times 10^{-8}$ & 0 & - & 0.09 \\
\hline Micro-tidal & $-6.9 \times 10^{-7}$ & -31 & $3.9 \times 10^{-7}$ & $5.0 \times 10^{-7}$ & -22 & 0.08 \\
\hline Macro-tidal & $-9.6 \times 10^{-7}$ & -5 & $2.6 \times 10^{-6}$ & $2.5 \times 10^{-6}$ & 1.8 & 0.09 \\
\hline Mega-tidal & $-1.0 \times 10^{-6}$ & 1 & $5.6 \times 10^{-5}$ & $5.0 \times 10^{-6}$ & 11 & 0.09 \\
\hline
\end{tabular}

${ }^{\text {a }}$ The mean vertical water flux $\overline{\boldsymbol{q}}$ was averaged across all but the first 3 days in VFLUX2 (due to the edge effects, see Figure 3 ) and all but the first day in 1DTempPro. The relative error refers to the error in the magnitude of the flux.

tidal amplitudes as tidal pumping begins to dominate (Table 1c). This is likely due to the system being better hydraulically constrained with higher amplitudes and head gradients. In this mode, 1DTempPro accurately estimates the amplitude in the $q$ variability across a tidal range, with relative error magnitudes $\leq 22 \%$. Also, when both the head and temperature data are analyzed in 1DTempPro, the root-mean-square errors (RMSE) for temperature compared to SUTRA results are low $\left(0.09^{\circ} \mathrm{C}\right)$, regardless of the tidal amplitude. Finally, 1DTempPro estimates hydraulic conductivity from the hydraulic gradient once the vertical water flux is inferred. The $K$ values estimated by 1 TTempPro were $7.4 \times 10^{-5}, 7.8 \times 10^{-5}, 1.1 \times 10^{-4}$, and $1.2 \times 10^{-4} \mathrm{~m} \mathrm{~s}^{-1}$ for no tide, micro-tidal, macro-tidal, and mega-tidal conditions, respectively. These values have a relative error magnitude $\leq 26 \%$ when compared to the SUTRA $K$ value $\left(1 \times 10^{-4} \mathrm{~m} \mathrm{~s}^{-1}\right)$. These errors are much lower than typical errors associated with other $K$ estimation techniques, which suggests that integrated temperature-head data can be useful for characterizing hydraulic properties of coastal sediment.

Results from the simulations with more complex (multiple periodic constituents) boundary conditions (Figure 4) were generally in agreement with the findings of the analyses with simpler periodic boundary conditions (Figure 3). The time series of water temperature and macro-tidal water level variations (Figure 4a and $4 \mathrm{~b}$ ) from the southwestern coast of Korea (Kim \& Cho, 2011) were converted to the frequency domain, resulting in the periodic constituents shown for temperature (Figure 4c) and level (Figure 4d), although the time series was likely too short to accurately characterize the spring-neap tidal constituent. The diurnal and semi-diurnal thermal constituents and diurnal, semi-diurnal, and spring-neap hydraulic constituents were used to drive a final SUTRA simulation. This run produced semi-diurnal porewater temperature data (Figure 4e) due to the combined diurnal and semi-diurnal thermal forcing (Figure 4a and 4c) and the oscillating fluid fluxes due to the macro-tidal conditions (Figure $4 \mathrm{~b}$ and $4 \mathrm{~d}$ ). When these SUTRA results were analyzed 
(a)

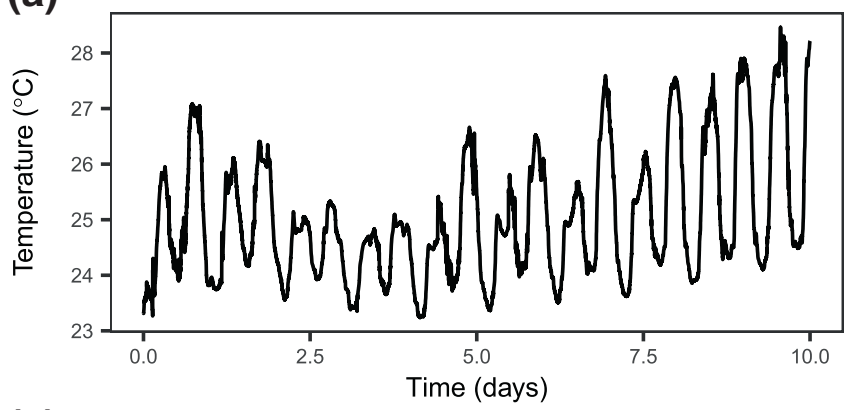

(c)

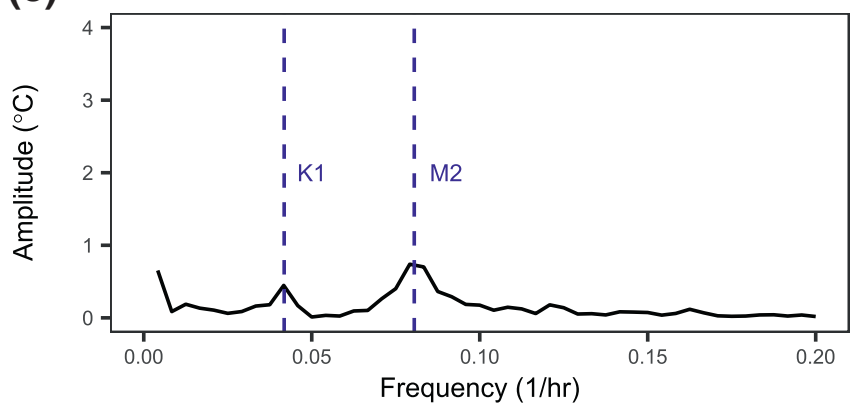

(e) Depths $(\mathrm{m})-0-0.1-0.2-0.3=0.5$

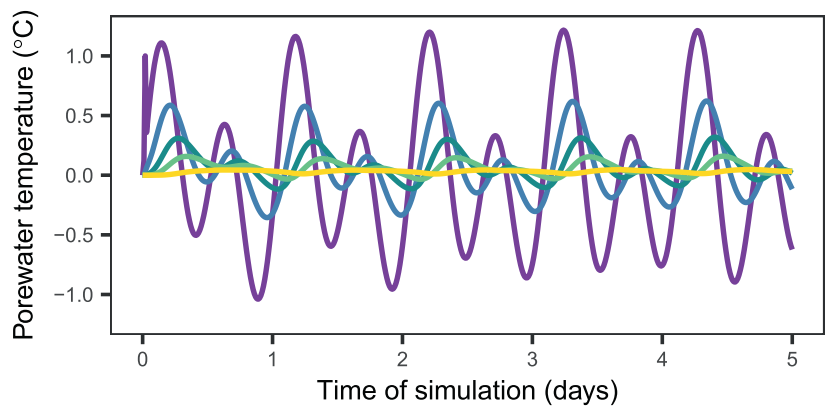

(b)

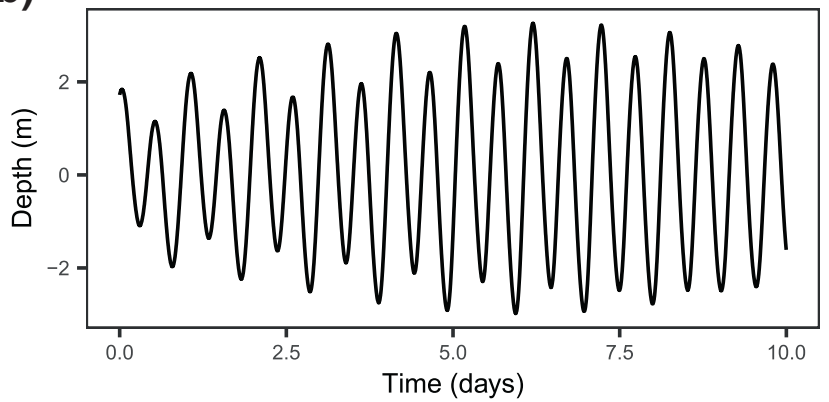

(d)

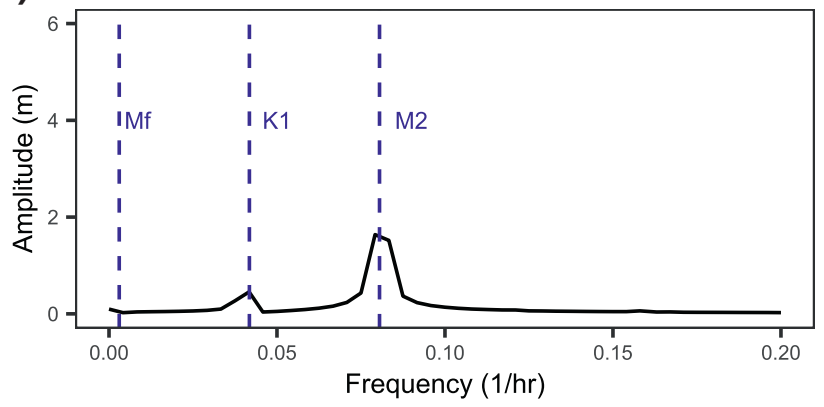

(f)

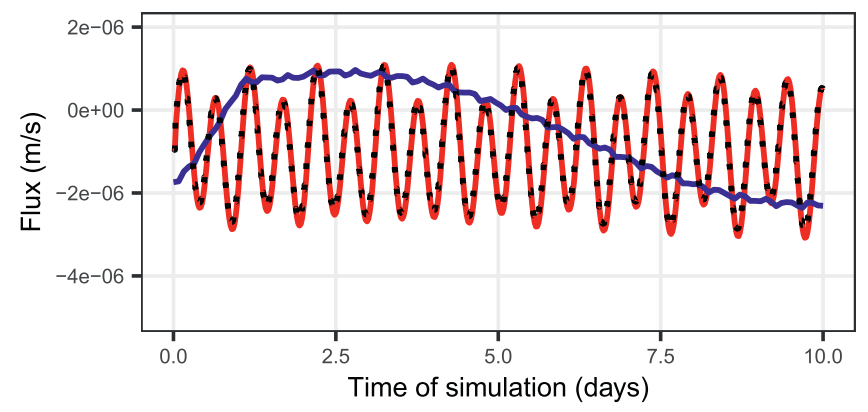

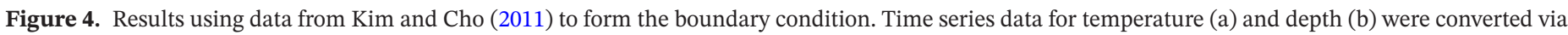

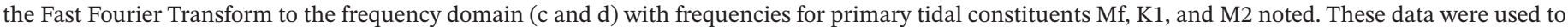
drive SUTRA simulations. SUTRA temperature results (e) were analyzed in VFLUX2 and 1DTempPro (f).

in VFLUX2 using the Hatch/Keery approach, the model performed well at estimating the mean flux over the simulation period (relative error $=4 \%$ ) but failed to reproduce intra-tidal flux variability (Figure $4 \mathrm{f}$ ). However, 1DTempPro with head data yielded an accurate time series of the high-frequency flux variation and direction change (Figure 4f), suggesting that our approach of using 1DTempPro with paired head and temperature data can be applied even with complex, superimposed periodic constituents for the surface boundary conditions.

\subsection{Further Considerations}

While we focused on tidal settings, hydraulic head oscillations in surface water bodies are also ubiquitous in inland environments due to diurnal variations in snowmelt (Caine, 1992; Kurylyk \& Hayashi, 2017), glacier melt (Condom et al., 2013), and evapotranspiration (Bond et al., 2002), as detailed in past reviews (Gribovszki et al., 2010; Lundquist \& Cayan, 2002). Furthermore, pronounced head oscillations and resultant variability in groundwater-surface water exchange can occur in managed river systems due to dam operations (Sawyer et al., 2009). In these settings, quantifying high-frequency temporal variability in groundwater-sur- 
face water exchanges is a critical challenge rarely investigated in the context of using heat as a tracer. Our results point to the potential for paired head and temperature data to accurately quantify the vertical water flux averaged across a diurnal or semi-diurnal head signal as well as the flux oscillations within a signal. The benefits of collecting combined temperature and hydraulic head data have been previously identified for flux and hydraulic conductivity estimates (Essaid et al., 2008; Hatch et al., 2010; Koch et al., 2016; Rahimi et al., 2015). However, we are not aware of prior studies showing the utility of combined head and temperature measurements for automatically inferring high-frequency flux variations, including flux direction reversals. In short, the solution to the inverse problem when using heat as a tracer is easier with the combination of head and temperature data, as the head data can yield the periodicity (phase, frequency, and relative amplitude) of the vertical flux variability, thereby limiting equifinality. This highlights the opportunity to embed pressure cells in sediment temperature probes designed for heat tracing (e.g., Thomle et al., 2020) as CTD (conductivity, temperature, and depth) loggers are normally too large for the required spacing. As our head difference between the top and bottom sensors was sometimes lower than $1 \mathrm{~cm}$, it is critical that high-accuracy/precision pressure cells are used or that the lower pressure logger be located further down the probe (e.g., $1 \mathrm{~m})$ than the depth $(0.2 \mathrm{~m})$ considered in our 1DTempPro examples. We acknowledge that such a probe design could be problematic in oblique flux conditions.

\section{Summary and Conclusions}

Although research activities focused on ocean-sediment exchanges have grown exponentially in recent years (Robinson et al., 2018; Taniguchi et al., 2019), we still lack inexpensive field instruments and techniques to accurately estimate high-frequency (i.e., sub-daily) flux time series. This makes it difficult to study water fluxes induced by bi-directional tidal pumping or to characterize the fresh component of submarine groundwater exchange. Applying heat as a hydrologic tracer is a potential solution to this problem; however, in comparison to the number of studies conducted in freshwater environments, heat has seldom been applied to trace vertical porewater exchanges beneath coastal waters.

In this study, we investigated how hydraulic oscillations due to tidal forcing drive periodic vertical water fluxes that in turn create complex heat advection patterns and impact sediment thermal regimes. Our numerical modeling (SUTRA) results revealed that porewater fluxes with high-frequency (sub-daily) variations in magnitude or even direction can cause the resultant diurnal temperature signals to become sawtooth rather than sinusoidal, even under perfectly sinusoidal thermal boundary conditions. We used standard heat as a tracer software tools (VFLUX2 and 1DTempPro) to analyze the SUTRA modeling results, infer vertical water fluxes, and compare the inferred water fluxes to the known water fluxes from SUTRA. The analytical methods in VFLUX2 were unable to reproduce vertical flux variability within a tidal cycle but reasonably estimated the mean vertical flux across tidal cycles. However, when we considered both temperature and hydraulic head as input to 1DTempPro, this model was able to accurately estimate the mean vertical water flux, the flux variability within a tidal cycle including flux direction reversals, and the sediment hydraulic conductivity.

Our results demonstrate that it is possible to use heat to trace groundwater-surface water exchange in tidal settings or other environments with high-frequency oscillations in vertical water fluxes. However, our approach requires that paired hydraulic head data be collected with multi-depth temperature data to estimate high-frequency vertical water fluxes, and that data analyses be conducted in a numerical software tool to consider head and temperature in conjunction. We hope that future studies will go beyond our modeling approach, which only varied boundary conditions, to consider the impacts of changing other system properties and to analyze collected field data. For example, further studies could investigate different mean fluxes or the impact of lower hydraulic conductivity material (Xin et al., 2012) for which fluxes influenced by matrix compressibility may be important even when total stress changes due to tides. We also highlight the opportunity to develop improved probes for measuring combined sediment porewater pressure and temperature data to trace vertical water fluxes. Use of subsurface temperature and pressure in combination with radioisotopes may allow researchers to more fully resolve spatial and temporal variability when quantifying ocean-sediment exchanges. 


\section{Data Availability Statement}

All models are publicly available online as detailed in their respective references. We provide model results as electronic supplementary files described in the supplementary read-me file.

\section{References}

\section{Acknowledgments}

We thank Jean Bahr, Alicia Wilson, Adam Haynes, and two anonymous reviewers for comments that allowed us to substantially improve our study. Yang-Ki Cho graciously shared the temperature and level data in Figure 4a and $4 \mathrm{~b}$. This research was undertaken thanks in part to funding from the Canada First Research Excellence Fund through the Ocean Frontier Institute. We also acknowledge the support of NSERC and the Canada Research Chairs Program. Funding for the 1DTempPro model analysis was provided by the National Science Foundation (EAR-1824820). Any use of trade, firm, or product names is for descriptive purposes only and does not imply endorsement by the U.S. Government.
Anderson, M. (2005). Heat as a ground water tracer. Ground Water, 43(6), 951-968. https://doi.org/10.1111/j.1745-6584.2005.00052.x Befus, K. M., Cardenas, M. B., Erler, D. V., Santos, I. R., \& Eyre, B. D. (2013). Heat transport dynamics at a sandy intertidal zone. Water Resources Research, 49(6), 3770-3786. https://doi.org/10.1002/wrcr.20325

Bokuniewicz, H., Pollock, M., Blum, J., \& Wilson, R. (2004). Submarine ground water discharge and salt penetration across the sea floor. Ground Water, 42(7), 983-989. https://doi.org/10.1111/j.1745-6584.2004.tb02637.x

Bond, B. J., Jones, J. A., Moore, G., Phillips, N., Post, D., \& McDonnell, J. J. (2002). The zone of vegetation influence on baseflow revealed by diel patterns of streamflow and vegetation water use in a headwater basin. Hydrological Processes, 16, 1671-1677. https://doi. org/10.1002/hyp.5022

Briggs, M. A., Lautz, L. K., Buckley, S. F., \& Lane, J. W. (2014). Practical limitations on the use of diurnal temperature signals to quantify groundwater upwelling. Journal of Hydrology, 519(B), 1739-1751. https://doi.org/10.1016/j.jhydrol.2014.09.030

Burnett, W. C., Aggarwal, P. K., Aureli, A., Bokuniewicz, H., Cable, J. E., Charette, M. A., et al. (2006). Quantifying submarine groundwater discharge in the coastal zone via multiple methods. The Science of the Total Environment, 367(2), 498-543. http://dx.doi.org/10.1016/j. scitotenv.2006.05.009

Burnett, W. C., Bokuniewicz, H., Huettel, M., Moore, W., \& Taniguchi, M. (2003). Groundwater and pore water inputs to the coastal zone. Biogeochemistry, 66, 3-33. https://doi.org/10.1023/B:BIOG.0000006066.21240.53

Caine, N. (1992). Modulation of the diurnal streamflow response by the seasonal snowcover of an alpine basin. Journal of Hydrology, 137, 245-260. https://doi.org/10.1016/0022-1694(92)90059-5

Condom, T. A., Rabatel, A., Villacis, M., Jacobsen, D., Dangles, O., Evolution, L., et al. (2013). Technical Note: Glacial influence in tropical mountain hydrosystems evidenced by the diurnal cycle in water levels. Hydrology and Earth System Sciences, 17, 4803-4816. https://doi. org/10.5194/hess-17-4803-2013

Constantz, J. (2008). Heat as a tracer to determine streambed water exchanges. Water Resources Research, 44(4), 1-20. https://doi. org/10.1029/2008WR006996

Cuthbert, M. O., \& Mackay, R. (2013). Impacts of nonuniform flow on estimates of vertical streambed flux. Water Resources Research, 49, 1-10. https://doi.org/10.1029/2011WR011587

Duque, C., Russoniello, C. J., \& Rosenberry, D. O. (2020). History and evolution of seepage meters for quantifying flow between groundwater and surface water: Part 2 - Marine settings and submarine groundwater discharge. Earth-Science Reviews, 204, 103168. https:// doi.org/10.1016/j.earscirev.2020.103168

Essaid, H., Zamora, C. M., McCarthy, K. A., Vogel, J. R., \& Wilson, J. T. (2008). Using heat to characterize streambed water flux variability in four stream reaches. Journal of Environmental Water Quality, 37(3), 1010-1023. https://doi.org/10.2134/jeq2006.0448

Freeze, R. A., \& Cherry, J. A. (1979). Groundwater. Englewood Cliffs, NJ: Prentice-Hall.

Gardner, L. R., \& Wilson, A. M. (2006). Comparison of four numerical models for simulating seepage from salt marsh sediments. Estuarine. Coastal and Shelf Science, 69, 427-437. https://doi.org/10.1016/j.ecss.2006.05.009

Gordon, R. P., Lautz, L. K., Briggs, M. A., \& McKenzie, J. M. (2012). Automated calculation of vertical pore-water flux from field temperature time series using the VFLUX method and computer program. Journal of Hydrology, 420(421), 142-158. https://doi.org/10.1016/j. jhydrol.2011.11.053

Goto, S., Yamano, M., \& Kinoshita, M. (2005). Thermal response of sediment with vertical fluid flow to periodic temperature variation at the surface. Journal of Geophysical Research: Solid Earth, 110(B1), B01106. https://doi.org/10.1029/2004JB003419

Gribovszki, Z., Szilagyi, J., \& Kalicz, P. (2010). Diurnal fluctuations in shallow groundwater levels and streamflow rates and their interpretation: A review. Journal of Hydrology, 385, 371-383. https://doi.org/10.1016/j.jhydrol.2010.02.001

Hatch, C. E., Fisher, A. T., Revenaugh, J. S., Constantz, J., \& Ruehl, C. (2006). Quantifying surface water-groundwater interactions using time series analysis of streambed thermal records: Method development. Water Resources Research, 42(10), W10410. https://doi. org/10.1029/2005WR004787

Hatch, C. E., Fisher, A. T., Ruehl, C. R., \& Stemler, G. (2010). Spatial and temporal variations in streambed hydraulic conductivity quantified with time-series thermal methods. Journal of Hydrology, 389, 276-288. https://doi.org/10.1016/j.jhydrol.2010.05.046

Healy, R. W., \& Ronan, A. D. (1996). Documentation of computer program VS2Dh for simulation of energy transport in variably saturated porous media: Modification of the US Geological Survey's computer program VS2DT. U.S. Geological Survey Water-Resources Investigations Report, 96-4230. https://doi.org/10.3133/wri964230

Hendershott, M., \& Munk, W. (1970). Tides. Annual Review of Fluid Mechanics, 2(1), 205-224. https://doi.org/10.1146/annurev. fl.02.010170.001225

Henderson, R. D., Day-Lewis, F. D., \& Harvey, C. F. (2009). Investigation of aquifer-estuary interaction using wavelet analysis of fiber-optic temperature data. Geophysical Research Letters, 36(6), 1-6. https://doi.org/10.1029/2008GL036926

Hutchinson, M. F., McKenney, D. W., Lawrence, K., Pedlar, J. H., Hopkinson, R. F., Milewska, E., \& Papadopol, P. (2009). Development and testing of Canada-wide interpolated spatial models of daily minimum-maximum temperature and precipitation for 1961-2003. Journal of Applied Meteorology and Climatology, 48(4), 725-741. https://doi.org/10.1175/2008JAMC1979.1

Irvine, D. J., Briggs, M. A., Lautz, L. K., Gordon, R. P., McKenzie, J. M., \& Cartwright, I. (2017). Using diurnal temperature signals to infer vertical groundwater-surface water exchange. Ground Water, 55(1), 10-26. https://doi.org/10.1111/gwat.12459

Irvine, D. J., Cranswick, R. H., Simmons, C. T., Shanafield, M. A., \& Lautz, L. K. (2015). The effect of streambed heterogeneity on groundwater-surface water fluxes inferred from temperature time series. Water Resources Research, 51(1), 198-212. https://doi. org/10.1002/2014WR015769

Irvine, D. J., Lautz, L. K., Briggs, M. A., Gordon, R. P., \& McKenzie, J. M. (2015). Experimental evaluation of the applicability of phase, amplitude, and combined methods to determine water flux rates from temperature time series using VFLUX 2. Journal of Hydrology, 5(5), 5. https://doi.org/10.1016/j.jhydrol.2015.10.054

Jacob, C. E. (1950). Flow of ground water. In H. Rouse (Ed.), Engineering hydraulics (pp. 321-386). Hoboken, NJ: John Wiley. 
Kawai, Y., \& Wada, A. (2007). Diurnal sea surface temperature variation and its impact on the atmosphere and ocean: A review. Journal of Oceanography, 63(5), 721-744. https://doi.org/10.1007/s10872-007-0063-0

Keery, J., Binley, A., Crook, N., \& Smith, J. W. N. (2007). Temporal and spatial variability of groundwater-surface water fluxes: Development and application of an analytical method using temperature time series. Journal of Hydrology, 336(1-2), 1-16. https://doi.org/10.1016/j. jhydrol.2006.12.003

Kim, T.-W., \& Cho, Y.-K. (2011). Calculation of heat flux in a macrotidal flat using FVCOM. Journal of Geophysical Research, 116, C03010. https://doi.org/10.1029/2010JC006568

Koch, F. W., Voytek, E. B., Day-Lewis, F. D., Healy, R., Briggs, M. A., Lane, J. W., \& Werkema, D. (2016). 1DTempPro V2: New features for inferring groundwater/surface-water exchange. Ground Water, 54(3), 434-439. https://doi.org/10.1111/gwat.12369

Kurylyk, B. L., \& Hayashi, M. (2017). Inferring hydraulic properties of alpine aquifers from the propagation of diurnal snowmelt signals. Water Resources Research, 53, 4271-4285. https://doi.org/10.1002/2016WR019651

Kurylyk, B. L., Irvine, D. J., \& Bense, V. F. (2019). Theory, tools, and multidisciplinary applications for tracing groundwater fluxes from temperature profiles. Wiley Interdisciplinary Reviews: Water, 6(1), e1329. https://doi.org/10.1002/wat2.1329

Kurylyk, B.L., Irvine, D. J., Mohammed, A. M., Bense, V. F., Briggs, A. M., Loder, J. W., \& Geshelin, Y. (2018). Rethinking the use of seabed sediment temperature profiles to trace submarine groundwater flow. Water Resources Research, 4595-4614. https://doi. org/10.1029/2017WR022353

Lautz, L. K. (2012). Observing temporal patterns of vertical flux through streambed sediments using time-series analysis of temperature records. Journal of Hydrology, 464, 199-215. http://dx.doi.org/10.1016/j.jhydrol.2012.07.006

Luce, C. H., Tonina, D., Gariglio, F. P., \& Applebee, R. (2013). Solutions for the diurnally forced advection-diffusion equation to estimate bulk fluid velocity and diffusivity in streambeds from temperature time series. Water Resources Research, 49, 488-506. https://doi. org/10.1029/2012WR012380

Lundquist, J. D., \& Cayan, D. R. (2002). Seasonal and spatial patterns in diurnal cycles in streamflow in the western United States. Journal of Hydrometeorology, 3, 591-603. https://doi.org/10.1175/1525-7541(2002)003<0591:SASPID>2.0.CO;2

McCabe, R. M., Estrade, P., Middleton, J. H., Melville, W. K., Roughan, M., \& Lenain, L. (2010). Temperature variability in a shallow, tidally isolated coral reef lagoon. Journal of Geophysical Research, 115, C12011. https://doi.org/10.1029/2009JC006023

McCallum, A. M., Andersen, M. S., Rau, G. C., \& Acworth, R. I. (2012). A 1-D analytical method for estimating surface water-groundwater interactions and effective thermal diffusivity using temperature time series. Water Resources Research, 48(11), W11532. https://doi. org/10.1029/2012WR012007

Michael, H. A., Mulligan, A. E., \& Harvey, C. F. (2005). Seasonal oscillations in water exchange between aquifers and the coastal ocean. Nature, 436(7054), 1145-1148. https://doi.org/10.1038/nature03935

Moore, W. S. (2010). The effect of submarine groundwater discharge on the ocean. Annual Review of Marine Science, 2(1), 59-88. https:// doi.org/10.1146/annurev-marine-120308-081019

Morris, S., \& Taylor, A. C. (1983). Diurnal and seasonal variation in physico-chemical conditions within intertidal rock pools. Estuarine, Coastal and Shelf Science, 17(3), 339-355. https://doi.org/10.1016/0272-7714(83)90026-4

Rahimi, M., Essaid, H. I., \& Wilson, J. R. (2015). The role of dynamic surface water-groundwater exchange on streambed denitrification in a first-order, low-relief agricultural watershed. Water Resources Research, 51(12), 9514-9538.

Rau, G. C., Andersen, M. S., McCallum, A. M., Roshan, H., \& Acworth, I. (2014). Heat as a tracer to quantify water flow in near-surface sediments. Earth-Science Review, 129, 40-58. https://doi.org/10.1016/j.earscirev.2013.10.015

Reckhardt, A., Beck, M., Seidel, M., Reidel, T., Wehrmann, A., Bartholoma, A., et al. (2015). Carbon, nutrient and trace metal cycling in sandy sediments: A comparison of high-energy beaches and backbarrier tidal flats. Estuarine. Coastal and Shelf Science, 159(20), 1-14. https://doi.org/10.1016/j.ecss.2015.03.025

Reeves, H. W., Thibodeua, P. M., Underwood, R. G., \& Garnder, L. R. (2000). Incorporation of total stress changes into the groundwater model SUTRA. Ground Water, 38(1), 89-98.

Robinson, C., Li, L., \& Barry, D. A. (2007). Effect of tidal forcing on a subterranean estuary. Advances in Water Resources, 30(4), 851-865. https://doi.org/10.1016/j.advwatres.2006.07.006

Robinson, C. E., Xin, P., Santos, I. R., Charette, M. A., Li, L., \& Barry, D. A. (2018). Groundwater dynamics in subterranean estuaries of coastal unconfined aquifers: Controls on submarine groundwater discharge and chemical inputs to the ocean. Advances in Water Resources, 115, 315-331. https://doi.org/10.1016/j.advwatres.2017.10.041

Russoniello, C. J., Heiss, J. W., \& Michael, H. A. (2018). Variability in benthic exchange rate, depth, and residence time beneath a shallow coastal estuary. Journal of Geophysical Research: Oceans, 123, 1860-1876. https://doi.org/10.1002/2017JC013568

Santos, I. R., Eyre, B. D., \& Huettel, M. (2012). The driving forces of porewater and groundwater flow in permeable coastal sediments: A review. Estuarine. Coastal and Shelf Science, 98, 1-15. https://doi.org/10.1016/j.ecss.2011.10.024

Sawyer, A. H., Cardenas, M. B., Bomar, A., \& Mackey, M. (2009). Impact of dam operations on hyporheic exchange in the riparian zone of a regulated river. Hydrological Processes, 23(15), 2129-2137. https://doi.org/10.1002/hyp.7324

Sawyer, A. H., Michael, H. A., \& Schroth, A. W. (2016). From soil to sea: the role of groundwater in coastal critical zone processes. Wiley Interdisciplinary Reviews: Water, 3(5), 706-726. https://doi.org/10.1002/wat2.1157

Stallman, R. W. (1965). Steady one-dimensional fluid flow in a semi-infinite porous medium with sinusoidal surface temperature. Journal of Geophysical Research, 70(12), 2821. https://doi.org/10.1029/JZ070i012p02821

Swain, E. D., \& Prinos, S. T. (2018). Using heat as a tracer to determine groundwater seepage in the Indian river Lagoon, Florida, April - November 2017. Reston, VA: U.S. Geological Survey Open File Report 2018-1151.

Swarzenski, P. W. (2007). U/Th series radionuclides as coastal groundwater tracers. Chemical Reviews, 107(2), 663-674. https://doi. org/10.1021/cr0503761

Taniguchi, M., Burnett, W. C., Cable, J. E., \& Turner, J. V. (2002). Investigation of submarine groundwater discharge. Hydrological Processes, 16(11), 2115-2129. https://doi.org/10.1002/hyp.1145

Taniguchi, M., Dulai, H., Burnett, K. M., Santos, I. R., Sugimoto, R., Stieglitz, T., et al. (2019). Submarine groundwater discharge: Updates on its measurement techniques, geophysical drivers, magnitudes, and effects. Frontiers in Environmental Science, 7, 141. https://doi. org/10.3389/fenvs.2019.00141

Thomle, J., Strickland, C., Johnson, T. C., Zhu, Y., \& Stegen, J. (2020). A flux detection probe to quantify dynamic groundwater-surface water exchange in the hyporheic zone. Ground Water, 58(6), 892-900. https://doi.org/10.1111/gwat.13001

Tirado-Conde, J., Engesgaard, P., Karan, S., Müller, S., \& Duque, C. (2019). Evaluation of temperature profiling and seepage meter methods for quantifying submarine groundwater discharge to coastal lagoons: Impacts of saltwater intrusion and the associated thermal regime. Water, 11(8), 1648. https://doi.org/10.3390/w11081648 
Voss, A. M., \& Provost, C. I. (2019). SUTRA, a model for saturated-unsaturated, variable density groundwater flow with solute or energy transport-documentation of generalized boundary conditions, a modified implementation of specified pressures and concentrations or temperatures, and the Lake. Techniques and methods report 6-A52. Reston, Virginia. https://doi.org/10.3139/9781569905586.002

Voytek, E. B., Drenkellfuss, A., Day-Lewis, F. D., Healy, R., Lane, J. W. J., \& Werkema, D. (2013). 1DTempPro: Analysing temperature profiles for groundwater/surface-water exchange. Ground Water, 52, 298-302. https://doi.org/10.1111/gwat.12051

Wilson, A. M., Woodward, G. L., \& Savidge, W. B. (2016). Using heat as a tracer to estimate the depth of rapid porewater advection below the sediment-water interface. Journal of Hydrology, 538, 743-753. https://doi.org/10.1016/j.jhydrol.2016.04.047

Xin, P., Kong, J., Li, L., \& Barry, D. A. (2012). Effects of soil stratigraphy on pore-water flow in a creek-marsh system. Journal of Hydrology, 475, 175-187. http://doi.org/10.1016/j.jhydrol.2012.09.047

\section{Reference From Supporting Information}

Bonan, G. (2015). Ecological climatology: Concepts and applications (3rd ed.). Cambridge: Cambridge University Press. https://doi. org/10.1017/CBO9781107339200 